\title{
El IAPH bucea y difunde las buenas prácticas para la activación del patrimonio cultural
}

El I Encuentro Patrimonio de Proximidad se celebró en mayo de 2018. La intención: visibilizar el trabajo de los agentes del patrimonio en conexión con el territorio. Resaltando otras formas de gestionarlo. Se pretendía un encuentro de experiencias. Algunas, invitadas por su trayectoria y reconocimiento. Otras, seleccionadas desde una convocatoria abierta al territorio. El resultado fue un Encuentro con un programa que reflejaba el trabajo de profesionales, colectivos y asociaciones vinculadas al patrimonio cultural con algo en común: llevar a cabo buenas prácticas en la activación del patrimonio cultural. La reflexión continuó en enero de 2019 con una segunda reunión de debate celebrada en la Casa del Pumarejo, ejemplo inspirador en la activación del patrimonio cultural desde la comunidad.

Isabel Luque Ceballos | Centro de Formación y Difusión del IAPH

URL de la contribución <http://www.iaph.es/revistaph/index.php/revistaph/issue/view/4356>

¿Y qué son "buenas prácticas"? Los criterios de valoración se establecieron en una primera reunión de trabajo y sirvieron de guía a lo largo de todo el proceso.y fueron los siguientes:

> Una gestión relacional, mapa de agentes equilibrado; $>$ Iniciativas abiertas, accesibles, inclusivas, integradoras;

$>$ Cercanas, que no localistas;

$>$ Medibles cuantitativa, pero también cualitativamente;

> Investigación situada en el territorio, hacia la salvaguarda del patrimonio y la autenticidad;

> Con proyección de futuro y viabilidad;

> De relevancia para la población local, implicación emocional e identitaria, facilitadores de vínculos sociales, apropiación del patrimonio por la comunidad, construcción de espacios de convivencia y relación;

$>$ Con el valor de sostenibilidad económica, social y ambiental;

A esta convocatoria se presentaron 45 proyectos de toda Andalucía, obteniendo un mapa vivo de experiencias de gestión del patrimonio cultural en el territorio desde lo local.

El Encuentro propició el debate entre personas vinculadas a proyectos como el del Campo Arqueológico de Mértola (http://www.camertola.pt/), la Red de Museos de

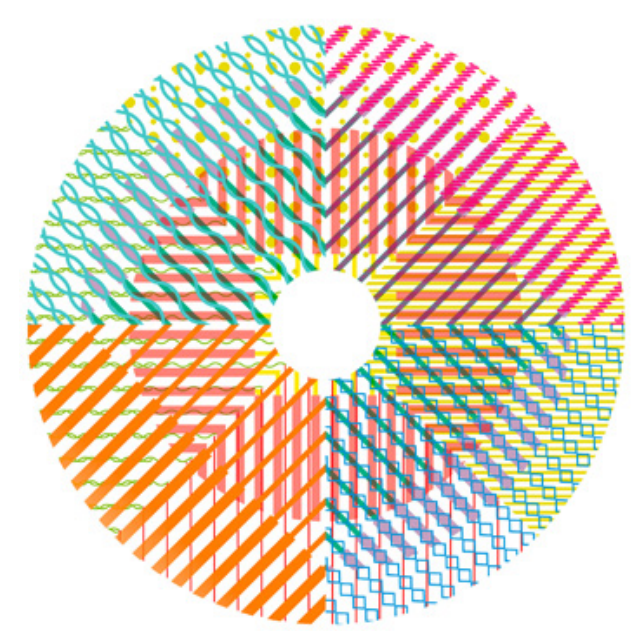

Logotipo de Readtívate

Lugo (http://lugo.gal/es/centros-tipos/red-de-museos), el Ecomuseo del río Caicena de Almedinilla (Córdoba) (http://www.ecomuseoriocaicena.es/), el Proyecto_Pax (patios de la Axerquía, Córdoba, https://www.facebook. com/patiosaxerquia/) y las estrategias de recuperación y puesta en valor del patrimonio que se están llevando a cabo en Alcalá la Real (Jaén) ${ }^{1}$. Surgieron reflexiones en torno a la participación ciudadana²: la necesidad de buscar mecanismos para que la ciudadanía ocupe espacios y se pueda articular la participación de manera real superando trabas administrativas y socioculturales. También alrededor del conflicto entre las corrientes 
centralizadoras y descentralizadoras porque, a menudo, las competencias están en un lugar y, los presupuestos, en otro. ¿Descentralización o multiplicación? Y sobre el concepto innovación: innovación es lo nuevo, pero también es la evolución de lo tradicional. $Y$ todo para hacer mejor nuestras vidas. Como explica Jesús Fernández de la Universidad de Oviedo, las innovaciones sociales "son nuevas ideas, procesos o tecnologías que, a la vez que cubren diferentes necesidades (de manera más eficaz, sostenible y justa que las alternativas), contribuyen a la creación de nuevas relaciones y/o colaboraciones intersectoriales" (FERNÁNDEZ, 2016). Otro de los retos planteados fue la financiación, con ejemplos como el proyecto Memola (Granada) (memolaproject.eu/es), impulsado gracias a la gestión de fondos europeos.

Las mesas se alternaron con sesiones de presentación de experiencias vinculadas a los criterios ya citados en las que la diversidad fue un común denominador y donde se habló de innovación social, de la necesidad de crear comunidades, lazos y conexiones, de las escalas tan diferentes de las iniciativas (en las que hay que diferenciar entre el autoempleo y las grandes empresas), etc. Se vieron en estas sesiones casos tan diversos y enriquecedores como la plataforma ciudadana Huelva te mira (https://www.facebook.com/huelvatemira/), el proyecto de Ecomuseo y agroecología contra la despoblación, Almocita en transición (Almería) ${ }^{3}$, la iniciativa editorial y de crowdfunding Revuelo en el museo (Sevilla) (https://www.facebook. com/revueloenelmuseo/), la participación en redes sociales \#CUATROCARAS del museo de Antequera ${ }^{4}$, la gestión del museo de la Rinconada (Sevilla) ${ }^{5}$, etc.

Completaron este encuentro experiencias prácticas como la del recreacionismo de la Colección museográfica de Gilena (https://www.facebook.com/coleccionmuseograficadegilena/), la acción artística de "semillas" de Miguel Ángel Moreno Carretero o la intervención musical y antropológica de Antropoloops. Iniciativas que son un ejemplo de la diversidad de formas que existen para abordar el patrimonio y de que cuando hablamos del pasado en el presente hablamos de personas.

Como conclusión, se extrae que las experiencias en la activación del patrimonio deben aspirar a ser: trans- versales e integradoras, con un mapa de agentes equilibrado; modelos abiertos, viables y adaptados a las nuevas formas de financiación; proyectos cercanos, que no localistas, resilientes, inclusivos, intergeneracionales y vinculados al territorio; procesos documentados, con evaluaciones que pongan el foco más en lo cualitativo que en lo cuantitativo; experiencias que trabajen con un modelo de Administración facilitadora.

La reunión de enero de 2019, que tuvo lugar en la sede de la Casa del Pumarejo, ejemplo de buenas prácticas en la activación del patrimonio cultural, consistió en una serie de mesas redondas integradas por agentes diversos, procedentes de la administración cultural en distintas escalas territoriales, asociaciones y colectivos, profesionales del patrimonio, la cultura, el turismo y la educación. Equipos que trabajaron desde "lo experiencial", tomando como eje inspirador y motivador el espacio que los acogía, para elaborar un documento colaborativo sobre cómo llevar a la práctica el buen hacer en la activación del patrimonio cultural. Se plantearon cuatro retos, extraídos de las conclusiones del I Encuentro de Patrimonio de Proximidad.

\section{$1^{\circ}$ Investigación aplicada al territorio y salvaguarda del patrimonio. Autenticidad e identidad}

La investigación es un proceso de gestión del conocimiento y de transferencia del mismo. Se trata de sumar agentes en el desarrollo del proceso para implicar a la ciudadanía y difundir los resultados.

La investigación debe formar parte de la gestión del patrimonio histórico. No se pueden dar las distintas facetas de la gestión (inventariado, catalogación, conservación, musealización, difusión, dinamización, formación...) sin investigación previa y/o paralela. Aunque la investigación está más vinculada tradicionalmente a la universidad (o a instituciones específicas como el CSIC) no debería ser exclusiva de estos ámbitos.

Científicos particulares, colectivos, asociaciones, empresas, fundaciones, museos locales o centros de patrimonio deben tener capacidad (a distintos niveles) para investigar, y debe ser reconocida esta capacidad investigadora por las administraciones. 
¿Cómo se podría llevar a cabo? Impulsando los centros de patrimonio como centros de investigación del territorio, promoviendo convenios con la Universidad que además ayudarían a legitimar aún más la labor de instituciones locales. Las administraciones deberían poner en contacto a los diferentes agentes.

La ciudadanía debe ser agente activo en la investigación, señalando el objeto de estudio en función de las necesidades o preocupaciones de cada territorio. Incorporándose al desarrollo del trabajo y a su difusión a distintos niveles, en función de la formación (necesaria para tener capacidad investigadora) que se tenga o que se procure específicamente para una investigación concreta.

En toda investigación deben promoverse: la interdisciplinariedad más que la multidisciplinariedad; el mecenazgo, con una ley acorde y atractiva para la inversión privada; y el micromecenazgo puntualmente. $Y$ debe facilitarse a la ciudadanía el acceso ágil a los resultados de todo tipo de investigaciones (respetando la propiedad intelectual).

¿Cómo se deberían relacionar los distintos agentes? Es importante tener el talante adecuado y formar a la persona investigadora. No obstante, el buen entendimiento con los agentes del patrimonio depende de voluntades individuales, cultivadas a través de los afectos. La investigación debería estar coordinada desde el territorio y la fórmula mixta (comités mixtos) entre investigadores de diferentes ámbitos/población (asociaciones) puede ser una buena solución.

\section{$2^{\circ}$ Mapa de agentes equilibrados}

Para ello es necesario una administración facilitadora, la creación de hábitos de participación y colaboración, cocreación y codecisión. Trabajo en red con los diferentes agentes.

¿Quiénes son los agentes que participan en la activación del patrimonio? Ciudadanía o tercer sector; administración, desde la más cercana territorialmente hasta la más lejana en esta escala. Sector micro-privado. La relación entre estos agentes se establece de forma diversa y es indispensable para su continuidad. Puede darse desde la tensión y el conflicto, el soporte institucional y legal, el impulso económico, la sensibilización, la escucha activa, la inducción y la toma de decisiones.

La generación de beneficios económicos puede provocar tensiones entre los agentes. No siempre es un factor de desarrollo, puede serlo también de desequilibrio.

¿Cómo llegar a un mapa equilibrado de agentes? Mediante la identificación de la población con su medio y su patrimonio, relacionándolo con el sector primario y la sostenibilidad económica, social y medioambiental de este territorio. Con escucha activa. Poner en práctica la participación es difícil, por eso se propone el ámbito de lo local para probar e innovar, ya que es más accesible en escala y medios para la codecisión y cogestión.

$3^{\circ}$ Retorno social y relevancia para la población local. Accesibilidad e integración. Proyectos cercanos que no localistas. Iniciativas intergeneracionales que fomenten la apropiación emocional.

¿Cómo conseguir el retorno social y su relevancia para la población? Visibilizando los logros y el patrimonio en la microeconomía social, una vez que la población se apropia de ella. Mediante el relevo generacional. Con pequeñas acciones y estrategias que construyan barrio desde los patrimonios y sus instituciones. Trabajando lo local y sus necesidades.

El reto es la apropiación emocional. Hay dos fórmulas: por adhesión o por construcción. La segunda es más potente, porque construye sentidos propios; si no hay codiseño no hay apropiación.

¿Qué papel tienen las instituciones? Son sujetos activos, en el papel de protección y soporte económico, legal y técnico. Establecen redes. Pero, si no hay una comunidad detrás que soporte el impulso de las administraciones, el patrimonio no se mantiene, necesita justificación social.

¿Relevante para la población el patrimonio, pero cómo? Mediante la creatividad, la remezcla y la transformación. 
Siendo sujetos activos. Detectando espacios de creación y activación. Desde una administración accesible y facilitadora. Resituando los mapas de agentes. A través del "afecto revolucionario".

¿En qué condiciones brota el afecto? Cuando se respeta la diversidad, la cooperación y se vuelve al grupo. El patrimonio es entonces una excusa para vivir.

\section{$4^{\circ}$ Gestión relacional}

Viabilidad, diversificación de fuentes de financiación.

¿Cómo hacer realidad la gestión compartida? Mediante la viabilidad de los proyectos, consiguiendo que tengan continuidad en el tiempo y financiación de múltiples fuentes. Poniendo en relación a las personas, ayudándolas a que construyan su idea de patrimonio, tejiendo redes.

En la legislación: buscar los huecos en los marcos jurídicos que existen e innovar en torno a los comunes y la gestión patrimonial alternativa (de la ciudadanía). La cultura y el patrimonio no son sectores marginales, sino derechos que deben tratarse en un marco más amplio.

En la transferencia, aprovechar la inteligencia colectiva, crear archivos de conocimiento. Utilizar el interés académico por experiencias. Buscar nuevas fórmulas de trabajo y experimentación. Midiendo los impactos que generan los proyectos, para revertir en ellos. Teniendo siempre presente que estos impactos no son sólo económicos (derivados del turismo), sino que en muchos casos pueden ser también sociales o culturales.

El patrimonio se mantiene por gente a la que le gusta enredarse y compartir con los demás. Esperando que esta energía tenga continuidad, nos vemos en próximo Encuentro de Patrimonio de Proximidad 2020.

Y, dado que el objetivo de redactívate es, además de generar redes, difundir y poner en valor las buenas prácticas de activación del patrimonio, queremos darle cabida en esta revista a algunos de los proyectos participantes. En esta ocasión os contamos, de la mano de sus impulsores, los proyectos Pax (pp. 13-15) y Antropoloops (pp. 10-12).

\section{NOTAS}

1. Ver entrevista a Carlos Calvo Aguilar en https://www. youtube.com/watch?v=HB1K9lvKdOk\&list=PLPyntzoR9s3rc4cqQ9XXtPESSE1YEdAgk\&index=10 [Consulta: 18/01/2019].

2. Es posible visualizar los contenidos íntegros de este debate en la dirección: https://www.youtube.com/watch?v=-YzT9S5hm40\&list=PLPyntzoR9s3rc4cqQ9XXtPESSE1YEdAgk\&index=11 [Consulta: 18/01/2019].

3. https://www.iaph.es/web/canales/formacion/cursos/Redactivate/almocitaentransicion.html [Consulta: 18/01/2019].

4. https://www.iaph.es/web/canales/formacion/cursos/Redactivate/museoantequera.html

[Consulta: 18/01/2019].

5. https://www.iaph.es/web/canales/formacion/cursos/Redactivate/museo_larinconada.html [Consulta: 18/01/2019].

\section{BIBLIOGRAFÍA}

- FERNÁNDEZ FERNÁNDEZ, J. (2016) Proyecto HESIOD. Definiendo e identificando ecosistemas de innovación socialpatrimonial. Revista $\mathrm{PH}, \mathrm{n} .{ }^{\circ}$ 90, 2016, pp. 236-239 [en línea] <http://www.iaph.es/revistaph/index.php/revistaph/article/ view/3824> [Consulta: 18/01/2019] 